\title{
Process mining: measuring key performance indicator container dwell time
}

\author{
Bambang Jokonowo ${ }^{1}$, Riyanarto Sarno ${ }^{2}$, Siti Rochimah ${ }^{3}$, Bagus Priambodo ${ }^{4}$ \\ ${ }_{1,2,3}$ Department of Informatics, Institut Teknologi Sepuluh Nopember, Surabaya, Indonesia \\ ${ }^{1}$ Department of Information Systems, Universitas Mercu Buana, Jakarta, Indonesia \\ ${ }^{4}$ Institute of Visual Informatics, Universiti Kebangsaan Malaysia, Selangor, Malaysia
}

\begin{tabular}{l} 
Article Info \\
\hline Article history: \\
Received Jan 18, 2019 \\
Revised Apr 22, 2019 \\
Accepted May 15, 2019 \\
\hline Keywords: \\
Control-flow \\
Cross-organizational \\
KPIs dwell time \\
Process discovery \\
Process mining
\end{tabular}

Corresponding Author:

Bambang Jokonowo, Department of Information Systems, Universitas Mercu Buana, Jalan Meruya Selatan No 1, Kembangan, Jakarta Barat, 11650, Indonesia. Email: bambang.jokonowo@mercubuana.ac.id

\begin{abstract}
The issues measures duration of stay the container logistic processes at ports in developing countries is often a major problem. Therefore, a knowledge process discovery, i.e., Heuristics Miner and Fuzzy Miner, can be used to discover the insight of process by creating a process model. The container import dwell time (DT) processes can be modeled based on the event log data sources are extracted from the terminal operating system (TOS). The $L^{*}$ life-cycle model is used to perform the process behavior analysis steps. The results of analysis and verification show that the container import DT processes have a median duration of 5.5 days and a mean duration of 6.07 days.
\end{abstract}

Copyright $@ 2019$ Institute of Advanced Engineering and Science. All rights reserved.

\section{INTRODUCTION}

Business processes can be analyzed to get the knowledge of process activities within the information system. The process can be modeled using the stored event log. The process of the model can then be analyzed from different perspectives, namely control flow, social network, roles and groups, performance, auditing and security, and decision rule [1]. The creation of a business process model based on the process recording of the event log is then called Process mining [1,2].

The process mining is an emerging discipline. The challenge of research opportunities in this area remains great, especially process mining for cross-organizational processes, which is not trivial process $[1,3]$. A port, for example, is a logistics company that carries out such a flow of process be handled with many of the organizations involved.

Process mining technique in this research is used to perform performance analysis based on the time perspective and role of the groups. The length of the container logistics process in ports is measured. The performance of the dwell time container process depends on the time of roles of container executor in the port. Not only the time but also the decisions of the executor in determining the duration of the container's stay in the port. Therefore, the actual movements of the container DT process can be detected using process mining techniques.

The researchers are already investigating the process of container dwell time [4-8], but no one has carried out the process mining approach. Though, the container DT process can be modeled using a real data event. Container DT Process is the time in which the container is accommodated at a certain part of the port. The duration of the container becomes one of the most important indicators of port 
efficiency [6]. Container DT processes show the productivity of the terminals and the overall operational efficiency of the terminals.

This study was conducted to show the performance of the port. The solution provided by the modeling of the process based on the process mining techniques, i.e., discovery, conformance, and enhancement. The advantage of using process mining techniques is based on real processes [1] and not on assumptions or simulation $[9,10]$. Therefore, the event $\log$ is used as the main point for analyzing the process.

The import container DT is a process instance that is executed together with other groups or organizations that have their respective roles and responsibilities. Process instance import container DT is a case in which the container process is moved from arrival at the port (unloading) to departure from the port area (truck out). A case runs through every event process from start to finish. There is no solution that can show which group makes the DT container process time-consuming and why it takes place [11]. Therefore, this research is conducted using process mining techniques to discover the real event process in a process model. The contribution of the research consists of extracting data, filtering it from different source data into the event log, creating a process models with the help of Heuristics Miner [12] and Fuzzy Miner [13] algorithms and performing analyses to measure Key Performance Indicators (KPIs) container import DT.

This paper contains section 2 that describes some research literature on import container DT, why import container DT is important, case study profiles. Section 3 explains the formalization of structured event $\operatorname{logs}$ and using the $L^{*}$ life-cycle model for implementing the phases of process mining. Section 4 Analysis and discussion, and the last section 5 are Conclusion and future research.

\section{LITERATURE REVIEW}

Suriadi [14] uses the $L^{*}$ Life-cycle methodology to observe the behavior of processes in Australian insurance companies. His main contribution discusses in detail challenges and experiences in the conception of key questions without business rules. For organizations that have not been analyzed using process mining, question-driven processes become important. At the beginning of the extraction of the conceptual data, the main question must be repeated in the question to be analyzed. Therefore, it is necessary to discuss with all process experts.

In contrast to research [14], this article analyses not only the process model but also the perspective of the organizational role. The author researches in different areas, namely the process domain in the port and in particular the handling of the import container DT process. A process is managed by more than one organization.Container DT process is the duration of the container within the port from the time of arrival (discharge) of the vessel to the delivery time received by the owner. Container DT process in relation to import load and vice versa for export [4]. In simple terms: the time between arrival and release of the cargo in port, time that determines port performance [6].

Import container DT, mentioned in the paper [5], is the time required in the order of the supply chain processes in the port. However, this paper only gives an idea of the container in the stacking area. While the DT import container is to cover the entire processing time with various participants in the port, it comes from the container in the port (discharge) to the container from the gate port (truck out).

The problem with importing DT containers into the paper $[4,5]$ is to determine the allocation of the storage space for a container. Considerations are being made because the problem of the container terminal, i.e., the container import process, is subject to a high degree of uncertainty [7]. This uncertainty is mainly due to a lack of coordination on the inland, and this situation is almost as common in developing countries. Therefore, proposes a collaborative logistics framework for a Port Logistics Chain [8]. And these researchers have not used real event data through the process of discovery as a model process.

The history of the container movement position within the port is recorded by the terminal operating system (TOS) and precisely recorded by the Differential Global Positioning System (DGPS). This tool offers an operational improvement of the process [15]. However, it has not explained in detail the time and model of the import container DT process. During the examination of the import container DT process, the event data of the process is taken from the Petikemas Surabaya (TPS) terminal. TPS is one of the logistic ports in Indonesia that conducts export and import business. TPS is an international trading gate through which the container can enter and exit. The process with other organizations such as customs, quarantine department and agent transport takes place via this port area.

\section{RESEARCH METHODE}

Process Mining creates a process model based on the event log. Several steps are necessary to perform the model process. The researchers used the $L^{*}$ life-cycle model [2] to conduct a study to analyze 
business performance using a real process model. Process Mining is a process-oriented process that is discovered on the basis of the event log. Therefore, the form of the formal event log structure must be observed first.

\subsection{Formalization of Structured Event Logs}

In this study, the formalization of the structured event protocol follows a method specified by Van der Aalst [2]. The definition of events and attributes is linked to the activities of the port terminal. The definitions A and B below give the formal definition, which is a requirement to prove a tree structure of the event $\log$. The tree structure of event $\log$ means a process consists of cases. A case consists of events such that each event relates to precisely one case. Events within a case are ordered and events have attributes. The examples of typical names are activity, time, and resource.

Definition A: event, attribute. Let $E$ be the set of all possible event identifiers at a port terminal. Events may be corresponds to an activity in the port area and characterized by various attributes, e.g., an event to move and stack a container, retrieved and loaded onto a truck, and also transported out of the port area, etc. All activities may have timestamps and executed by a resource as particular person or group. In most situations, activities take time. The timestamps should be non-descending in the event log. Therefore, events may point out the start or completion of activities. For any event $e \in E . A(e)$ is the activity associated to event $e . T(e)$ is the timestamp of event $e . S(e)$ is the resource associated to event $e$.

Definition B: case, trace, event $\log$. Let $C$ be the case. A case is the life-cycle activities of the process at the port container terminal. For any event $c \in C$. Each case has a special mandatory attribute trace. $R(c) \in E^{*}$, traces in a $\log$ contain at least one event, and $\hat{c}=R(c)$ is a shorthand for referring to the trace of a case. A trace is a finite sequence of events $\sigma \in E^{*}$ such that event appears only once, i.e., for $1 \leq i<j \leq$ $|\sigma|: \sigma(i) \neq \sigma(j)$. An event $\log$ is a set of cases $G \subseteq C$ such that each event appears at most once in the entire $\log$, i.e., for any $c_{1}, c_{2} \in G$ such that $c_{1} \neq c_{2}: \partial_{\text {set }}\left(\hat{c}_{1}\right) \cap \partial_{\text {set }}\left(\hat{c}_{2}\right)=\emptyset$. If an event log contains timestamps, then the ordering in a trace should respect these timestamps, i.e., for any $c \in G, i$ and $j$ such that $1 \leq i<$ $j \leq|\hat{c}|: T(\hat{c}(i)) \leq T(\hat{c}(j))$. $\{A(e) \mid c \in G \wedge e \in \hat{c}\}$ is the set of all activities appearing in $\log G$. $\{a \in A \mid c \in G \wedge a=A(\hat{c}(1)) \wedge a=A(\hat{c}(|\hat{c}|))\}$ is the set of all activities that served as start and end activity for the same case. After the formal event logs are known, then the $L *$ life-cycle model stages are performed.

\section{2. $L^{*}$ life-cycle Model}

The $L^{*}$ life-cycle model in Figure 1 was introduced by Van der Aalst to improve the process through process mining technique. This method is the type of lasagna appropriate to the logistical case [2]. The lasagna type means a well-structured process. Therefore, this method is used to investigate the case of the DT container import process in one of the logistics ports in Indonesia.

Stage 0 planning and justifying. In this phase determines the goals, planning, and reasons why the process discovery research and what benefits are achieved. Stage 1 extract. In this phase, data extraction is performed to create an event log that is controlled by questions. Questions are selected to determine the scope of the process and measure dwell time KPIs. The process mining procedure is used to carry out the analysis, and the results are used to improve operational processes. Therefore, we need to measure the time-related KPIs [16]. The KPIs measured in the import container DT process are lead time, service time, waiting time and synchronization time.

The lead time can also refer to the flow time of the total time from the start to the end of the case. It can also be measured by the average cycle time of all cases. However, the variance level is very important because the time difference between all existing cases will be different. For example, a case lasts more or less than two weeks, or only a few hours or even more than a month. Therefore, the percentage of all cases whose lead time is less than the threshold value is called the service level, for example, the percentage of all cases that are processed within one month.

The service time is the time a case passes through, which can be measured per case or can also be used for all cases. The waiting time is the time a case is waiting for a resource to become available. This time can be measured per activity or for the entire case. The synchronization time is the time of an activity that has not yet been fully enabled and is waiting to be triggered by outside or another parallel branch. The waiting activity is due to the need for synchronization. Unlike the waiting time, the activity is fully enabled.

Level 2 creates the control flow and connects the event log. Check the event log flow, then perform repeated filter analyses and discover them with the ProM and DISCO tools.

Step 3 creates an integrated process model. Analyze how it can improve the process model by adding the organizational perspective and improving the model process by adding a time perspective. The result of level 3 is also the answering and interpretation of selected questions and the taking of suitable 
measures, i.e., adjusting, designing, and intervening. The process model can be filtered with the Heuristic miner [17].

The meaning of a process instance in process mining is a process that is characterized by the start of the activity and the end of the activity in the form of the event sequence. The sequence of the different events is referred to as the trace, as shown in Table 1. The sequence of the traces forms different cases. If we want to find out which case is the fastest and the longest in the process, we do not cut it off or filter it by calendar time, but rather we look for the lead time of a case. This way is an important definition that underlies the collection of data from various sources of information, whether by the calendar time or the basis of the occurrence of the process.

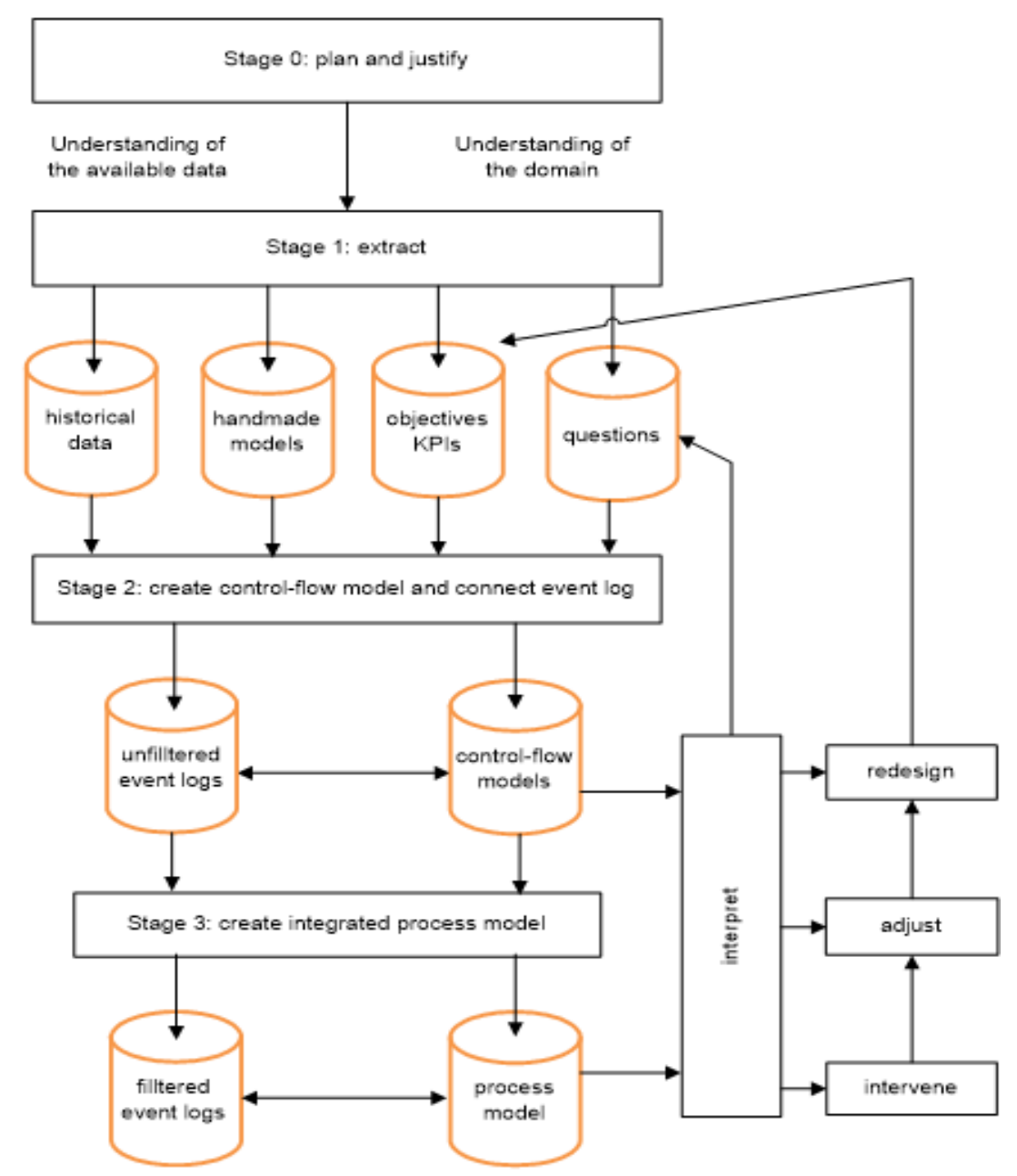

Figure 1. Methode L* life-cycle model (simplified)

If a lead time of the longest case is not more than one month, then we can take the data in one month. But if the longest case can be more than a month, we can take data in a year. The first example, if we take data based on the calendar month range of the 7th month to the 9th month (July, August, and September), then there is the possibility of data processing is truncated in months 7,8 and 9. The second example, if we take the dates based on the process that takes place in the calendar of the 7th to 9th month (July, August, and September). Then there may be dates that begin and end between the 7th, 8th and 9th month.

It is important to be defined at the beginning with the data owner or user. Therefore, the import container DT process is filtered according to the process that takes place within the evaluation month. If the performance process container DT is evaluated within the month, the process must be completed in the month. For example, the container DT process is evaluated at the 7th month; then it looks it started from the previous months, as shown in Figure 2. 
If the purpose of process mining is to analyze the perspective of control flow, social network, roles and groups, auditing and security and decision rule, the frequency of event counts is taken into account. However, if the analysis is based on a performance perspective, the time span (duration) in the process must be used. Heuristic mining [18] can be used to estimate the duration of the activity instance [2].

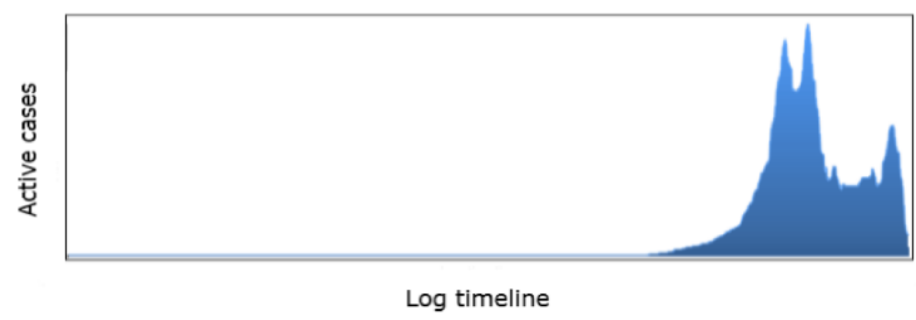

Figure 2. Duration of time all cases

\section{ANALYSIS AND DISCUSSION}

After our research plan was approved by the Board, we then conducted interviews and discussions with the Information Technology Manager and the Port Operations Manager. The general overviews obtain for the next intensive discussion of the import container DT process. Based on the method of research, we then conducted a discussion with Business Process Analyst Manager to understand the domain of the import container DT process. The discussion result is in a handmade model Figure 3 . The discussion shows that the process container imports DT instance, starting from the first activity (discharge) to the last activity (truck out). Then right from the beginning, we analyzed there are may be possible of traces, cases, events and the other corresponding attributes.

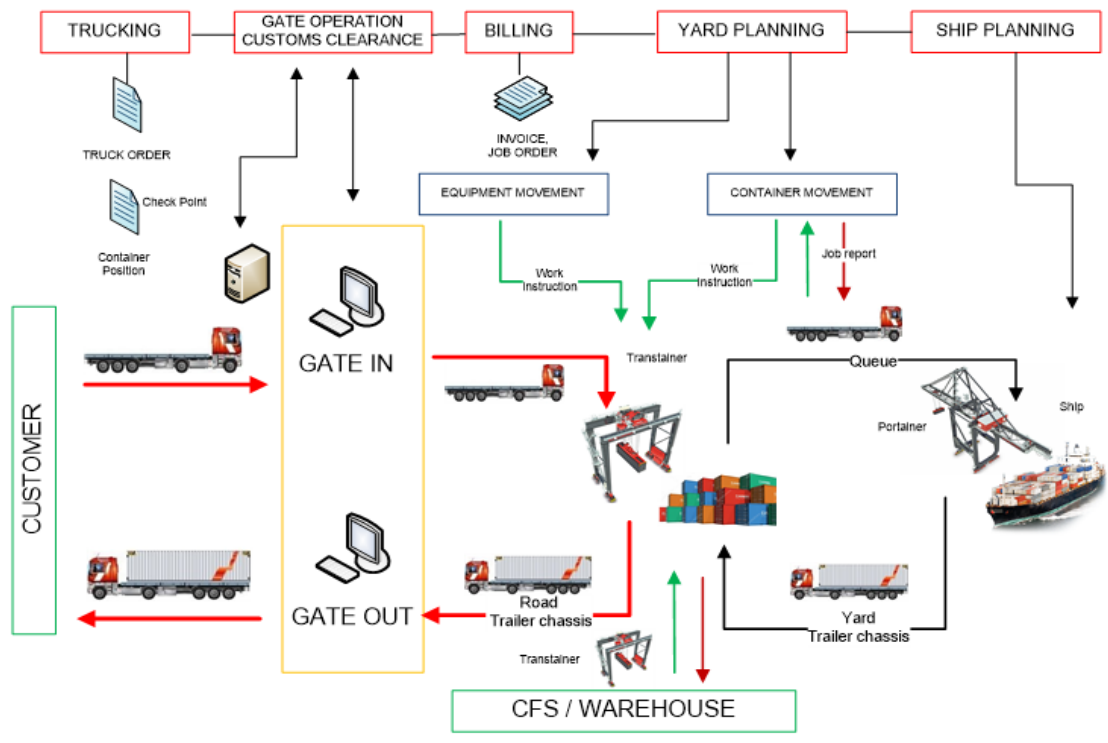

Figure 3. Handmade model

Furthermore, we were introduced to TOS Database Administrator to retrieve historical data container import DT process. The cooperation is important because we need a table of related data, understand syntax and semantic form codes. This activity is done until we agree to get the cycle data process. Data were taken to measure key performance indicators for three months, i.e., July, August, and September of 2015 .

Based on the understanding of the business process domain and the availability of data obtained then we form a standard event log. Event logs are simplified in the form of an event label based on the format of the event log structure Table 1 . The event log file data is then converted into XES format. 
At the time of extraction of data to create event log. Uncleaned event logs are filtered using disco tools. This tool uses a fuzzy mining approach to create a control flow model. The control flow model has known all the activities that exist in the process, as shown in Table 2. Based on our control flow model we repeatedly discussed with business process manager and the operational executive team who know the real process of import container DT. In parallel, this activity is done by doing filtering event log data.

Table 1. Pieces of event $\log$

\begin{tabular}{cccc}
\hline CaseID & ActivitiesLabel & TimeStamps & GroupsLabel \\
\hline 664 & $\mathrm{~A}$ & $03 / 01 / 2015$ 07:40:23 & $\mathrm{G} 1$ \\
664 & $\mathrm{~B}$ & $03 / 01 / 2015$ 08:21:27 & $\mathrm{G} 2$ \\
664 & $\mathrm{~N}$ & $31 / 07 / 201510: 23: 45$ & $\mathrm{G} 6$ \\
664 & $\mathrm{O}$ & $31 / 07 / 201519: 21: 52$ & $\mathrm{G} 6$ \\
664 & $\mathrm{P}$ & $31 / 07 / 201519: 39: 22$ & $\mathrm{G} 6$ \\
795 & $\mathrm{~A}$ & $02 / 01 / 201515: 26: 33$ & $\mathrm{G} 1$ \\
795 & $\mathrm{~B}$ & $02 / 01 / 201515: 39: 41$ & $\mathrm{G} 2$ \\
795 & $\mathrm{~N}$ & $31 / 07 / 201510: 23: 45$ & $\mathrm{G} 6$ \\
\hline
\end{tabular}

Table 2. Activities of import container DT

\begin{tabular}{ll}
\hline Label & \multicolumn{1}{c}{ Activity } \\
\hline A & Discharge \\
B & Stack Date \\
C & Job BHD \\
D & Move_to_BHD_LOC \\
E & Job_BHD_Complete \\
F & Return_BHD_move_to_Yard \\
G & Job_Change_Status \\
H & Move_to_CFS \\
I & JComplete_Stripping \\
J & Return_RS_Move_to_Yard \\
K & Quarantine_Job_BHD \\
L & Move_to_TPFT \\
M & Quarantine_Job_BHD_Complete \\
N & Job_DEL_Date \\
O & Truck IN (Ext) \\
P & Truck OUT \\
\hline
\end{tabular}

Simultaneously with data extraction and filtering to focus on the scope of process container import, a question-driven one is as follows:

How long is the dwell time of the import container? KPIs are measured by the lead time of all cases,

Which is the fastest case and which is the longest case? A case

Which group is the highest frequency? Roles and Groups

Different event logs can be extracted from the same data set. That depends on the question and point of view chosen. Once an event log has been created, it is usually filtered, and filtering itself is an iterative process. At the beginning of the data, the extraction becomes an event log. Data filtering starts with a coarsegrained scoping up to a fine-grained scoping.

It is also important to exclude incomplete data at the time of filtering [2]. Due to the control flow, some cases start with activity A, N or B (discharge, job_del_date, stack date) and must remove the incomplete case in this case. Therefore, the import container DT process starts with activity A (Discharge), it is necessary to filter only the cases that start from A, which we will analyze. This is a complete case.

Similarly, for the activity at the end of a case, based on the control flow, some cases end with activity (N, O, P or E). Meanwhile, the import container DT process is at the end of activity P (truck out). Therefore, we remove the data of various cases whose activities do not end with $\mathrm{P}$. The results of the initial analysis and filtering of the data can be seen at Table 3.

The event $\log$ with activity filtering is very important because we want to eliminate data inconsistency or focus only on the best data we will analyze. In disco tools, we use the endpoint filtering function to determine the start and end activity. Incomplete cases must be removed. Also, these filter activities are repeated and communicated with business process managers and database administrators. Sometimes the original records need to be repaired because after the cleanup by filtering there was an invalid source data.

The end result is the quality of the model process, which is determined from the event log according to the real state of the import container DT process Figure 4, Figure, and Figure 6. In Figure 4 using fuzzy 
miner [13, 19] formed clusters 17, 18, and 19. Formation of cluster based on the proximity of activities that form cluster group G3 (customs behandle) with frequency 0.098 consisting of 4 items, that is $\mathrm{C}, \mathrm{D}, \mathrm{E}$, and F. Cluster group G4 (change status FCL-LCL) with frequency 0.063 consisting of 4 items, that is G, H, I, and J. The cluster group G5 (quarantine behandle) with frequency 0.070 consisting of 3 items, that is K, L, and M. However, after further analysis that the activities in the cluster independent of activity $\mathrm{B}$. The sequence of cluster is dependent and triggered by other organizations. Similarly, for N activity is independent of activity $\mathrm{B}$ and triggered by any participant, while activity $\mathrm{N}$ has a high frequency of 0.587 . To get the more detail information about the dependency decision of clusters 17, 18 and 19, and activity $\mathrm{N}$, we need data messages as a trigger of the sequences of activities from the other organizations. In this way, the synchronization time can be determined.

Table 3. Scoping data through filtering

\begin{tabular}{lll}
\hline Data & Coarse-grained scoping & Fine-grained scoping \\
\hline Cases & 102,340 & 102,328 \\
Events & 531,585 & 531,524 \\
Trace variant & 49 & 41 \\
Start & $02 / 01 / 201515: 26$ & $02 / 01 / 201515: 26$ \\
End & $30 / 09 / 201523: 47$ & $30 / 09 / 201523: 47$ \\
\hline
\end{tabular}

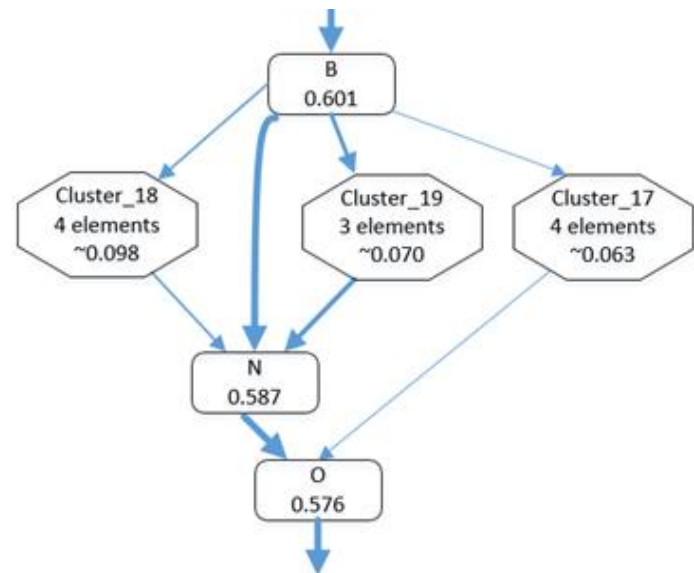

Figure 4. Clustering of group of activities

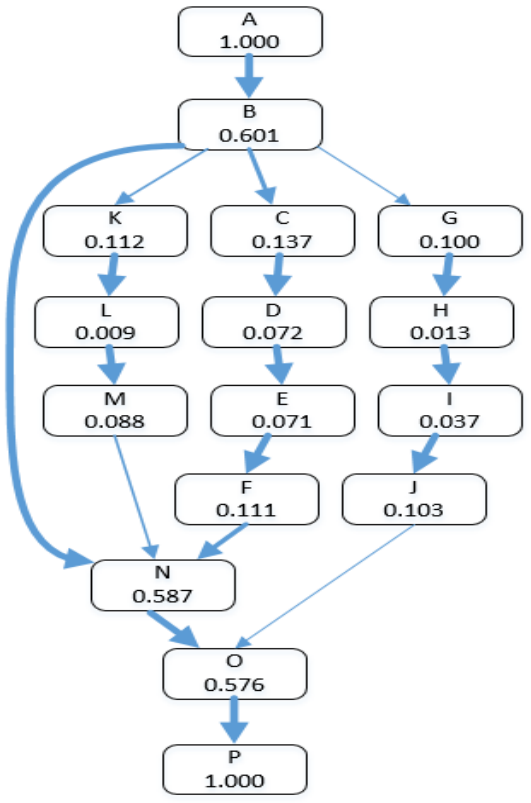

Figure 5. Discovery using fuzzy miner

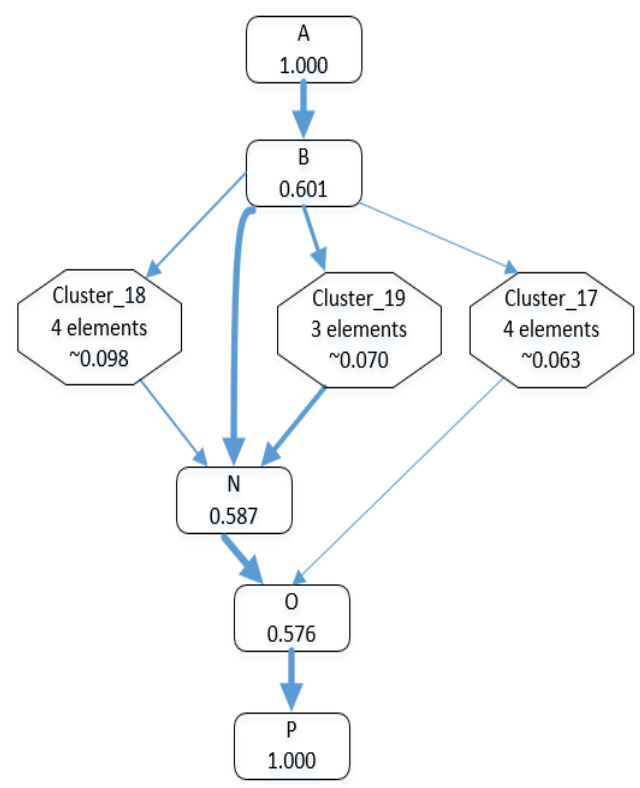

Figure 6. Clustering model 


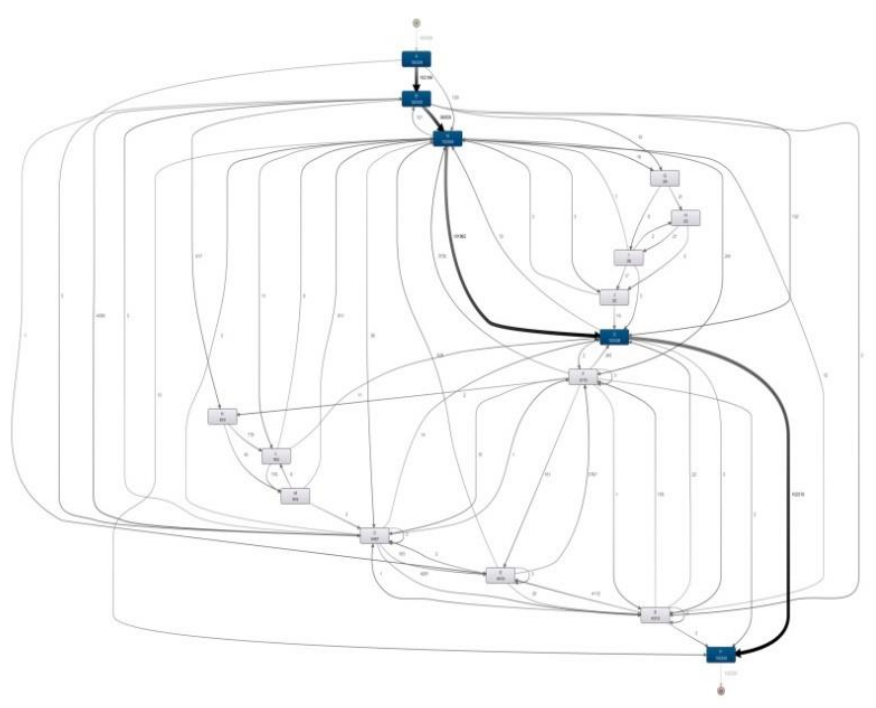

Figure 7. Discovery using disco

\section{DISCUSSION}

Through discussions with business process Managers, Database Administrators, and the operational team to perform event log data filters and generated control flow models. We analyze the control flow model and know the frequency of each activity and group, see Table 4-5. Furthermore, after the control flow, the discovery process generates a model process. We can analyze the frequency of each group, for example in July. The largest frequency performed by G6 (delivery) amounted to $57.75 \%$, see Table 5.

Table 4. Roles group

\begin{tabular}{cl}
\hline Group Label & Group Activities \\
\hline G1 & berth discharge \\
G2 & yard discharge \\
G3 & customs behandle \\
G4 & change status FCL-LCL \\
G5 & quarantine behandle \\
G6 & delivery \\
\hline
\end{tabular}

Table 5. Frequency in July

\begin{tabular}{ccc}
\hline Resource & Frequency & Relative frequency \\
\hline G1 & 26920 & $19.25 \%$ \\
G2 & 26919 & $19.25 \%$ \\
G3 & 4629 & $3.31 \%$ \\
G4 & 47 & $0.03 \%$ \\
G5 & 563 & $0.40 \%$ \\
G6 & 80760 & $57.75 \%$ \\
\hline
\end{tabular}

The objective KPIs are measured by calculating the mean and median lead time of all cases. The results of the measurement can be seen in Table 6 . The calculated results using the process mining techniques are then compared and verified with reports from the company within the same time frame. The reporting timeframe in July, August, and September can be seen in Table 6.

Table 6. Dwell Time measurement comparison

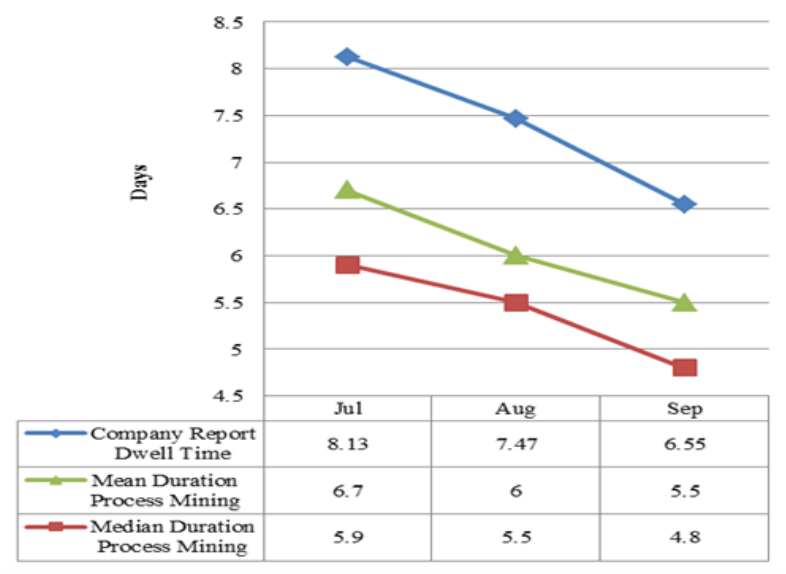


We get additional insights using process mining techniques, in detail we can analyze and search a case that is the fastest or the longest case. We can see in Table 7 and Table 8. The fastest case is caseID 580, ANBOP activity, duration 1 hour 6 mins, Table 7. It can be seen that the ANBOP trace, in this case, differs from the mainstream model process in Figure 5, when activity $\mathrm{N}$ is not followed by activity $\mathrm{B}$. The longest case is in caseID 795, ABNOP activity, with duration 210 days 5 hours, Table 9.

Table 7. Key performance indicator dwell time

\begin{tabular}{|c|c|c|c|c|c|c|c|c|}
\hline Month & Start & End & Cases & Events & Trace & Activities & \multicolumn{2}{|c|}{ Case Duration (day) } \\
\hline 7 & $\begin{array}{c}02 / 01 / 2015 \\
15: 26\end{array}$ & $\begin{array}{c}31 / 07 / 2015 \\
23: 47\end{array}$ & 26,920 & 139,838 & 27 & 16 & $\begin{array}{c}\text { Median } \\
5.90\end{array}$ & $\begin{array}{c}\text { Mean } \\
6.70\end{array}$ \\
\hline 8 & $\begin{array}{c}15 / 02 / 2015 \\
05: 23\end{array}$ & $\begin{array}{c}31 / 08 / 2015 \\
23: 53\end{array}$ & 40,515 & 210,440 & 25 & 16 & 5.50 & 6.00 \\
\hline 9 & $\begin{array}{c}02 / 05 / 2015 \\
21: 07\end{array}$ & $\begin{array}{c}30 / 09 / 2015 \\
23: 47\end{array}$ & $\begin{array}{c}34,893 \\
102,328\end{array}$ & $\begin{array}{l}181,246 \\
531,524\end{array}$ & 29 & 16 & $\begin{array}{r}4.80 \\
5.50\end{array}$ & $\begin{array}{r}5.50 \\
6.07\end{array}$ \\
\hline
\end{tabular}

Table 8 . The fastest case

\begin{tabular}{lllll}
\hline Activity & Resource & Date & Time & Duration \\
\hline A & G1 & $06 / 07 / 2015$ & $10: 52$ & 9 mins, 40secs \\
N & G6 & $06 / 07 / 2015$ & $11: 02$ & $17 \mathrm{mins}, 22 \mathrm{secs}$ \\
B & G2 & $06 / 07 / 2015$ & $11: 20$ & $28 \mathrm{mins}, 30$ secs \\
O & G6 & $06 / 07 / 2015$ & $11: 48$ & 11 mins, 4secs \\
P & G6 & $06 / 07 / 2015$ & $11: 59$ & \\
\hline
\end{tabular}

Table 9. The longest case

\begin{tabular}{lllll}
\hline Activity & Resource & Date & Time & Duration \\
\hline A & G1 & $02 / 01 / 2015$ & $26: 33$ & 13mins, 8secs \\
B & G2 & $02 / 01 / 2015$ & $39: 41$ & 209days, 8hours \\
N & G6 & $31 / 07 / 2015$ & $23: 45$ & 10hours, 12mins \\
O & G6 & $31 / 07 / 2015$ & $35: 47$ & 40mins, 25secs \\
P & G6 & $31 / 07 / 2015$ & $16: 12$ & \\
\hline
\end{tabular}

We can analyze that activity B performs service time 209 days 8 hours, and $\mathrm{N}$ has to wait for it (waiting time). However, after a further investigation based on Figure 4 clustering group that $\mathrm{N}$, in this case, is not influenced by group activity in the clustering. We need to explore the next analyzed about the required of others data attribute.

\section{CONCLUSION AND FUTURE RESEARCH}

Performance of port (KPIs) import container DT process can be measured by applying the lead time of all cases. KPIs for 3 months all cases were median duration 5.5 days and mean duration 6.07 days. In addition, KPIs are compared between corporate reports and process mining measurement results. The results are verified and show the same performance.

The result, in detail, can be analyzed the occurrence of noise in a case. To find the fastest case in caseID 580, then its activity is ANBOP, duration 1 hour 6 minutes. Searching for the longest case found caseID 795, its activity ABNOP, and duration 210 days 5 hours. The analysis results also show activities with a high frequency of $\mathrm{N}$ of 0.587 and frequency $\mathrm{O}$ of 0.576 .

Finally, process mining can be used to measure the performance of KPIs that import the DT container process. And we can set the target to be achieved by improving performance in detail through outlier analysis of a case. We can identify the cause of the fast and slow process, and then we can make process improvements. We can also analyze the activities or group of organizations involved in the process.

Further research is a model merging process analysis, which is created by adding a perspective of organizational collaboration. The structure of the event $\log$ is distinguished between the $\log$ of document flow and the log of process physically. Process mining is used for measuring the synchronization time of a collaborative supply chain management system for a seaport logistics chain. 


\section{ACKNOWLEDGEMENTS}

Thanks to Mr. Amin Jamal as Information Technology Manager, Iman as Business Process Analyst Manager, Database Administrator Terminal Operation System, and Port Operation Team, and TPS Board of Directors.

\section{REFERENCES}

[1] W. van der Aalst, A. Adriansyah, A.K.A. de Medeiros, F. Arcieri, T. Baier, T. Blickle, J.C. Bose, P. van den Brand, R. Brandtjen, J. Buijs, A. Burattin, J. Carmona, M. Castellanos, J. Claes, J. Cook, N. Costantini, F. Curbera, E. Damiani, M. de Leoni, P. Delias, B.F. van Dongen, M. Dumas, S. Dustdar, D. Fahland, D.R. Ferreira, W. Gaaloul, F. van Geffen, S. Goel, C. Günther, A. Guzzo, P. Harmon, A. ter Hofstede, J. Hoogland, J.E. Ingvaldsen, K. Kato, R. Kuhn, A. Kumar, M. La Rosa, F. Maggi, D. Malerba, R.S. Mans, A. Manuel, M. McCreesh, P. Mello, J. Mendling, M. Montali, H.R. Motahari-Nezhad, M. zur Muehlen, J. Munoz-Gama, L. Pontieri, J. Ribeiro, A. Rozinat, H. Seguel Pérez, R. Seguel Pérez, M. Sepúlveda, J. Sinur, P. Soffer, M. Song, A. Sperduti, G. Stilo, C. Stoel, K. Swenson, M. Talamo, W. Tan, C. Turner, J. Vanthienen, G. Varvaressos, E. Verbeek, M. Verdonk, R. Vigo, J. Wang, B. Weber, M. Weidlich, T. Weijters, L. Wen, M. Westergaard, M. Wynn, Process Mining Manifesto, (2012) 169-194. doi:10.1007/978-3-642-28108-2_19.

[2] W.M.P. der Aalst, Process Mining: Discovery, Conformance and Enhancement of Business Processes, 1st ed., Springer Publishing Company, Incorporated @2011, 2011.

[3] B. Jokonowo, J. Claes, R. Sarno, S. Rochimah, Process Mining in Supply Chains: A Systematic Literature Review, Int. J. Electr. Comput. Eng. 8 (2018). doi:10.11591/IJECE.V8I6.PP\%P.

[4] S. Soul, K. Mola, Determinants of Container Dwell Time : the Case Study of Mombasa Port, (2010).

[5] M. Gaete G., M. C. González-Araya, R. G. González-Ramírez, C. Astudillo H., A Dwell Time-based Container Positioning Decision Support System at a Port Terminal, Proc. 6th Int. Conf. Oper. Res. Enterp. Syst. (2017) 128139. doi:10.5220/0006193001280139.

[6] C. Ducruet, H. Itoh, O. Merk, Time Efficiency at World Container Ports, Int. Transp. Forum. (2014) 30. www.internationaltransportforum.org/jtrc/DiscussionPapers/jtrcpapers.html\% 5Cnwww.internationaltransportforum .org/jtrc/DiscussionPapers/jtrcpapers.html\%5Cnwww.internationaltransportforum.org/jtrc/DiscussionPapers/jtrcpap ers.html.

[7] Y. Pahala, The Determinants of Port Servqual and Their Implications on the Container Port Performance : An Empirical Study on Container Terminal Ports in Indonesia, 19 (2017) 1-14. doi:10.9790/487X-1912020114.

[8] L.M. Ascencio, R.G. González-Ramírez, L.A. Bearzotti, N.R. Smith, J.F. Camacho-Vallejo, A collaborative supply chain management system for a maritime port logistics chain, J. Appl. Res. Technol. 12 (2014) 444-458. doi:10.1016/S1665-6423(14)71625-6.

[9] R. Setiawan, R. Sarno, A.C. Fauzan, Evaluation of container forecasting methods for analyzing port container terminal performance using agent-based simulation, 2018 Int. Conf. Inf. Commun. Technol. ICOIACT 2018. 2018January (2018) 286-291. doi:10.1109/ICOIACT.2018.8350718.

[10] R. Rahardianto, R. Sarno, G. Intani Budiawati, Performance Time Evaluation of Domestic Container Terminal Using Process Mining and PERT, Proc. - 2018 Int. Semin. Appl. Technol. Inf. Commun. Creat. Technol. Hum. Life, ISemantic 2018. (2018) 469-475. doi:10.1109/ISEMANTIC.2018.8549768.

[11] E. Skoufias, M. Rabassa, S. Olivieri, M. Brahmbhatt, Why Cargo Dwell Time Matters in Trade, Management. 2010 (2012) 1-5. doi:10.2139/ssrn.1686004.

[12] A.J.M.M. Weijters, J.T.S. Ribeiro, Flexible heuristics miner (FHM), IEEE SSCI 2011 Symp. Ser. Comput. Intell. CIDM 20112011 IEEE Symp. Comput. Intell. Data Min. 334 (2011) 310-317. doi:10.1109/CIDM.2011.5949453.

[13] C.W. Günther, W.M.P. van der Aalst, Fuzzy Mining - Adaptive Process Simplification Based on Multi-perspective Metrics, (2007) 328-343. doi:10.1007/978-3-540-75183-0_24.

[14] S. Suriadi, M.T. Wynn, C. Ouyang, A.H.M. Ter Hofstede, N.J. Van Dijk, Understanding process behaviours in a large insurance company in Australia: A case study, Lect. Notes Comput. Sci. (Including Subser. Lect. Notes Artif. Intell. Lect. Notes Bioinformatics). 7908 LNCS (2013) 449-464. doi:10.1007/978-3-642-38709-8_29.

[15] A. Jamal, R. Sarno, H. Ginardi, Analyzing the benefit of implementing integrated dgps and terminal operating system at yard terminal Surabaya, J. Theor. Appl. Inf. Technol. 95 (2017) 948-959.

[16] A. Adriansyah, Performance Analysis of Business Processes from Event Logs and Given Process Models, (2009).

[17] A.J.M.M. Weijters, W.M.P. Van Der Aalst, A.K.A. De Medeiros, Process Mining with the Heuristics Miner Algorithm, Tech. Univ. Eindhoven, Tech. Rep. WP. 166 (2006) 1-34. doi:10.1.1.118.8288.

[18] A. Burattin, R. Sperduti, Heuristics miner for time interval, in: Lect. Notes Bus. Inf. Process., 2015: pp. 85-95. doi:10.1007/978-3-319-17482-2_11.

[19] B.F. Van Dongen, A. Adriansyah, Process mining: Fuzzy clustering and performance visualization, Lect. Notes Bus. Inf. Process. 43 LNBIP (2010) 158-169. doi:10.1007/978-3-642-12186-9_15. 


\section{BIOGRAPHIES OF AUTHORS}
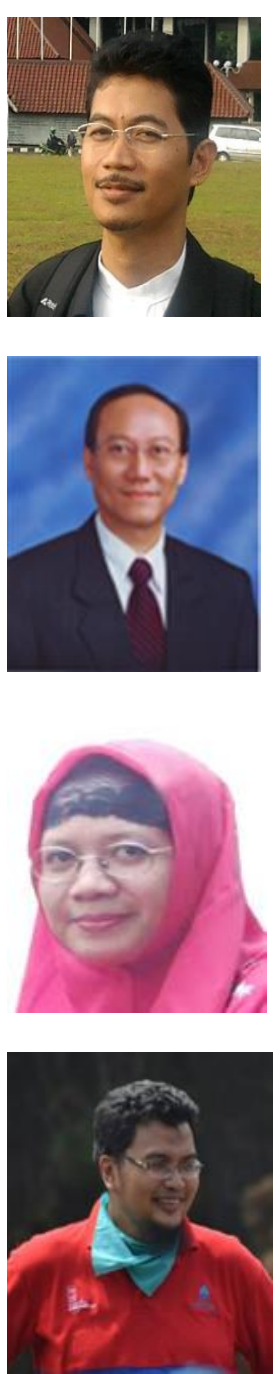

Bambang Jokonowo is a researcher at Informatics Engineering, Sepuluh Nopember Institute of Technology, Indonesia. His research focus on the process mining and he is also a member of the research team in Lab-Based Education (LBE) Enterprise Intelligent System at https://lbeifits.wordpress.com/about-us/ . He is teaching Business Process Modeling course at Universitas Mercu Buana, Jakarta.

Riyanarto Sarno is a Professor in Informatics Engineering, Sepuluh Nopember Institute of Technology, Indonesia. He earned Ir in Electronical Engineering at Institut Teknologi Bandung, DrsEc in Economic at Pajajaran University. He received MSc (1988) and PhD (1992) in Computer Science from the University of New Brunswick UNB Canada. His research interests include Process Mining, semantic web service, Semantic ERP. He is a leader of Lab-Based Education (LBE) Enterprise Intelligent System, and He has published journal and conference paper at https://lbeifits.wordpress.com/

Siti Rochimah is a lecturer in Informatics Engineering, Sepuluh Nopember Institute of Technology, Indonesia. She receives a master degree at Institut Teknologi Bandung and doctoral degree at University Technology Malaysia. Her research interests are in software quality assurance and software evolution.

Bagus Priambodo is a lecturer in Information System department, Universitas Mercu Buana, Indonesia. He receives a master degree at Universitas Indonesia and now pursuing $\mathrm{PhD}$ at Universiti Kebangsaan Malaysia. His research interests is in machine learning and mobile apps. 